\title{
Effect of dietary probiotics on colon length in an inflammatory bowel disease-induced murine model: A meta-analysis
}

\author{
Sung-II Ahn, (1) Sangbuem Cho, $\odot$ and Nag-Jin Choi* (1) \\ Department of Animal Science, Jeonbuk National University, Jeonju 54896, Korea
}

\section{ABSTRACT}

We investigated the effect of probiotic supplementation on inflammatory bowel disease (IBD) by metaanalysis. We included 30 studies to assess the effect of probiotic administration. We estimated the effect size using standardized mean difference, and we evaluated the statistical heterogeneity of the effect size using Cochran's Q test, followed by meta-ANOVA and metaregression analysis to explain the heterogeneity of the effect size using a mixed-effects model. We conducted Egger's linear regression test to evaluate publication bias. Among the factors evaluated, colon length and myeloperoxidase showed the greatest $\mathrm{Q}$ statistic and $I^{2}$ index, respectively. Colon length, transforming growth factor- $\beta$, IL-10, superoxide dismutase, and glutathione showed positive effect sizes in the fixed- and randomeffects models. The others (spleen weight, tumor necrosis factor $\alpha$, IL-1 $\beta$, IL-6, IL-12, IL-17, IFN- $\gamma$, disease activity index, thiobarbituric acid reactive substances, nitric oxide, myeloperoxidase, malondialdehyde, histological score, and macroscopic inflammatory score) showed negative effect sizes in the fixed- and randomeffects models. Probiotics showed a significant effect on all investigated factors, except IL-10. In meta-ANOVA and meta-regression analysis, Lactobacillus paracasei was the most effective probiotic for colon length. Lactobacillus paracasei, Lactobacillus reuteri, Lactobacillus fermentum, and a mixture of Lactobacillus bulgaricus and Saccharomyces boulardii (LC $+\mathrm{SB}$ ) were effective for colon length, tumor necrosis factor $\alpha$, IL-6, IL-10, IFN- $\gamma$, and disease activity index. Lactobacillus rhamnosus was most effective for IL-10 and IFN- $\gamma$. Dietary probiotics are effective in improving the symptoms of IBD. Although the results of this meta-analysis had some limitations due to a lack of animal experiments, they will be meaningful to people with IBD.

Key words: meta-analysis, probiotics, inflammatory bowel disease

Received July 30, 2019.

Accepted October 11, 2019.

*Corresponding author: nagjin@jbnu.ac.kr

\section{INTRODUCTION}

Inflammatory bowel disease (IBD) includes ulcerative colitis and Crohn's disease. These diseases present with various symptoms, including loss of BW, bloody stool, fever, and contraction of colon length; in some cases, they progress to colorectal cancer (Kim and Chang, 2014). However, the etiology of IBD is still unclear (Krawisz et al., 1984; Weitzman and Gordon, 1990; Fiocchi, 1998; Hendrickson et al., 2002). Although the underlying causes of IBD have not been clearly elucidated, they are thought to be caused by a distorted immune response of the intestinal mucosa because of various environmental factors (Sartor, 2008). Among these environmental factors, the representative factor is the gut microbiota. Approximately 500 to 1,000 species of bacteria inhabit the human intestine (Salzman and Bevins, 2008). They form a varied and complex ecology and maintain an anaerobic environment in the intestine. They simultaneously absorb nutrition and control the immune response. The gut microbiota is well balanced in healthy people, but an unbalanced status of the gut microbiota leading to the growth of a harmful microbiome in the intestine - dysbiosis - induces a proinflammatory immune response. Consequently, the inflammatory response associated with IBD increases (Tamboli et al., 2004). For example, the microbiome associated with normal bowel function decreases in people with IBD (Frank et al., 2007; Franke et al., 2008; Scanlan and Marchesi, 2008), fungal presence is increased (Kühbacher et al., 2006; Ott et al., 2008) or methanogen diversity is reduced (Scanlan and Marchesi, 2008). Recently, the gut microbiota has become a major determinant of intestinal and non-intestinal diseases, based on the theory that IBD is related to the intestinal microflora, a concept that is supported by the differences in intestinal microflora between healthy individuals and people with IBD (Tamboli et al., 2004; Guinane and Cotter, 2013).

Probiotics are live microorganisms that help in maintaining good health, including gut health and intestinal homeostasis (Fuller, 1989; Hill et al., 2014), and they are useful for improving gut health as well (Hemara- 
jata and Versalovic, 2013). Some studies have reported positive effects of probiotics in IBD. Rembacken et al. (1999) reported that well-defined nonpathogenic Escherichia coli Nissle 1917 was effective in preventing the recurrence of IBD compared with placebo. Saccharomyces boulardii relieved the symptoms of IBD and reduced the risk of relapse (Guslandi et al., 2000). Consequently, probiotics may be considered good alternatives for the prevention or management of IBD.

Generally, glucocorticoid and sulfasalazine have been used to treat IBD, but they come with serious side effects (Misiewicz et al., 1965; Boumpas et al., 1993). Many studies have been conducted to discover probiotics that have no side effects. Generally, probiotics are known to be effective in alleviating IBD, improving intestinal mucosa, regulating cytokines, preventing colon cancer, and improving the immune system (Guarner and Schaafsma, 1998).

In murine models, the symptoms of IBD can be improved with probiotic supplementation. However, only a few comprehensive studies have investigated the specific effects of probiotics in improving the symptoms of IBD. The objective of this study was to conduct a meta-analysis of the effect of probiotics on colon length and changes in other indicators in murine IBD models.

\section{MATERIALS AND METHODS}

\section{Data Set}

We performed a literature search using the Preferred Reporting Items for Systematic Reviews and MetaAnalysis (PRISMA; Liberati et al., 2009; Moher et al., 2009). We searched the following online databases: ScienceDirect (Elsevier B. V., Amsterdam, the Netherlands) and PubMed (United States National Library of Medicine, Bethesda, MD). The key words we used in both databases were "probiotics," "IBD," "rat," and "mice." Our search initially located 857 and 157 articles from ScienceDirect and PubMed, respectively. We screened all articles by title, abstract, and full text. We excluded review articles and studies at the cell culture level or studies investigating the administration of micro- or nanoencapsulated probiotics. We included studies that investigated changes in colon length and the immune system after the feeding of probiotics. A total of 30 studies exploring 19 factors were extracted and used to evaluate the effect of probiotic supplementation in a murine IBD model. We included studies that had an IBD group as a control; that induced IBD in the model using chemicals such as dextran sodium sulfate (DSS), 2,4,6-trinitrobenzene sulfonic acid (TNBS), dinitrobenzene sulfonic acid (DNBS), or oxazolone; and that provided measured data with standard deviation or standard error.

\section{Data Analysis}

Corrected standardized mean difference (Hedge's g) and $95 \%$ confidence intervals were calculated for the control and treatment groups. The weight of the effect size was computed using inverse variance (Borenstein et al., 2009; Deek et al., 2011). Effect-size analysis of fixed- and random-effects models was used to calculate the summary effect due to differences in experimental period, sample size, animal strain, and dose of probiotics in each study. To assess the statistical heterogeneity of the effect size, we performed Cochran's Q test; we investigated the ratio of true heterogeneity to total variation in the observed effects with the $I^{2}$ index. We also conducted meta-ANOVA and meta-regression analyses to explain the heterogeneity of the effect size in mixedeffects models for factors with degrees of freedom $>10$. We used means of control and treatment, number of replications, and standard deviations for within-study error as parameters in the effect-size calculations for both the fixed- and random-effects models. In the random-effects model, we added the tau square value $\left(\tau^{2}\right)$ to the variance calculation to consider within- and between-study variance together. Finally, we performed a publication bias analysis to verify the validity of the study results. Statistical analysis and visualization of the results were conducted using the packages meta, tidyverse, and metafor in the $\mathrm{R}$ statistical program (version 3.5.3; R Development Core Team, 2019, http:/ /www.r-project.org).

\section{RESULTS AND DISCUSSION}

\section{Data Set}

The data sets and experimental conditions from the 30 published studies are summarized in Table 1. The included studies were published between 2004 and 2019. Most of the studies $(\mathrm{n}=23)$ were conducted using mouse strains such as $\mathrm{C} 57 \mathrm{Bl} / 6, \mathrm{BALB} / \mathrm{c}$, Swiss Albino, TLR4lps-/lps-, and ICR; the others used rat strains, including Wistar, Sprague-Dawley, and NC/ Nga. The most common chemical used to induce IBD was DSS, and Lactobacillus plantarum and Lactobacillus casei were the most common probiotic strains used for supplementation.

\section{Effect Size and Heterogeneity Analysis}

Table 2 shows the effect of probiotics on IBD in mice and rats using fixed- and random-effects models. Fac- 
Table 1. Studies used in the data set and information for meta-analysis

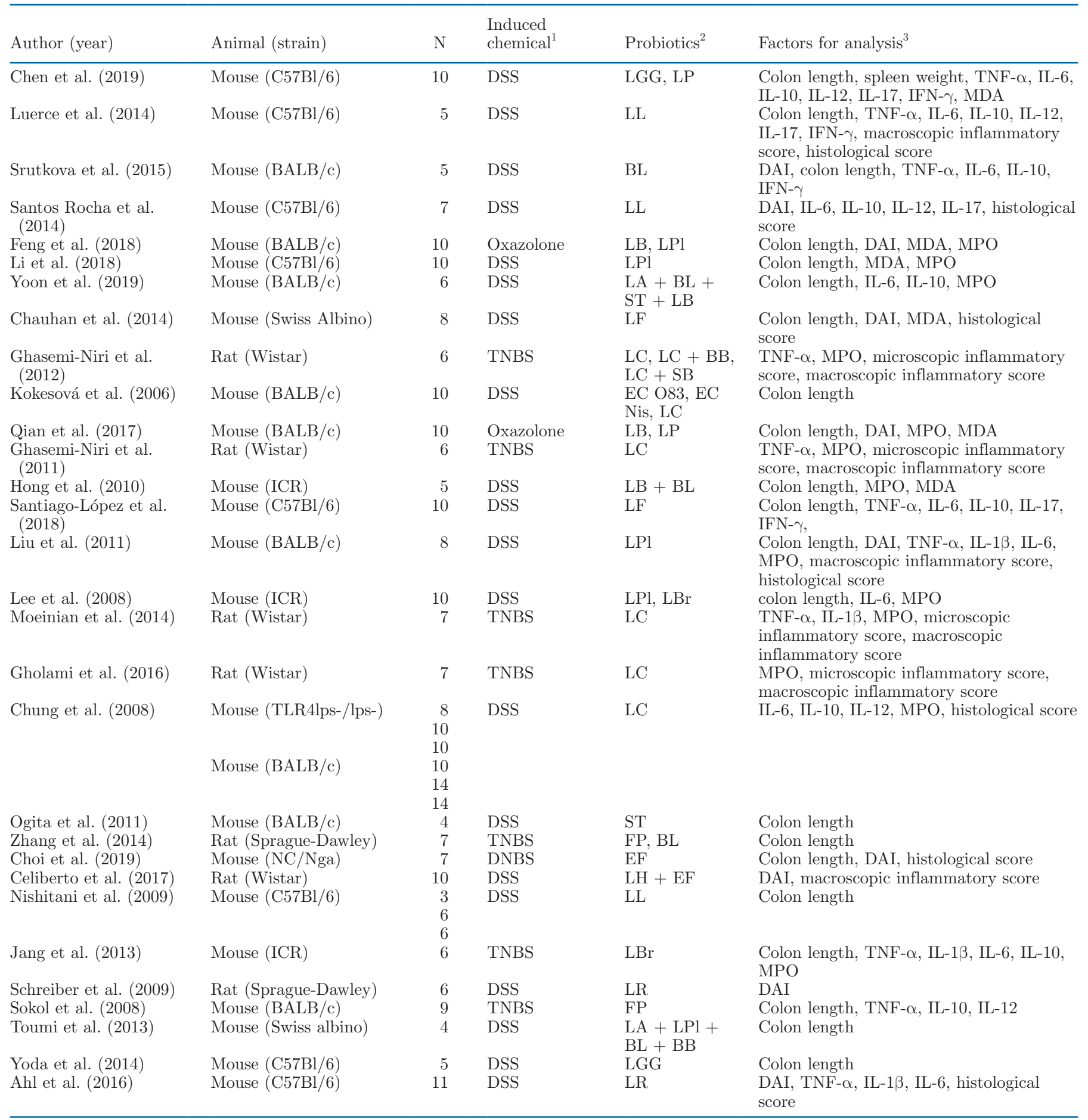

${ }^{1}$ DNBS $=$ dinitrobenzene sulfonic acid; DSS $=$ dextran sodium sulfate; TNBS $=2,4,6$-trinitrobenzenesulphonic acid.

${ }^{2} \mathrm{BB}=$ Bifidobacterium bifidum $; \mathrm{BL}=$ Bifidobacterium longum $; \mathrm{EF}=$ Enterococcus faecalis $; \mathrm{FP}=$ Faecalibacterium prausnitzii $; \mathrm{LA}=$ Lactobacillus acidophilus; $\mathrm{LB}=$ Lactobacillus bulgaricus $; \mathrm{LBr}=$ Lactobacillus brevis; $\mathrm{LC}=$ Lactobacillus casei $; \mathrm{LF}=$ Lactobacillus fermentum; LGG $=$ Lactobacillus rhamnosus GG; LH = Lactobacillus helveticus; $\mathrm{LL}=$ Lactobacillus lactis; $\mathrm{LP}=$ Lactobacillus paracasei; $\mathrm{LPl}=$ Lactobacillus plantarum $; \mathrm{LR}=$ Lactobacillus reuteri $; \mathrm{SB}=$ Streptococcus boulardii $; \mathrm{ST}=$ Streptococcus thermophilus; EC O83 = Escherichia coli $\mathrm{O} 83 ; \mathrm{EC}$ Nis $=$ Escherichia coli Nissle.

${ }^{3} \mathrm{DAI}=$ disease activity index; $\mathrm{MDA}=$ malondialdehyde $\mathrm{MPO}=$ myeloperoxidase; TNF- $\alpha=$ tumor necrosis factor $\alpha$. 
tors such as colon length, transforming growth factor (TGF- $\boldsymbol{\beta}$ ), IL-10, superoxide dismutase, and glutathione showed positive effect sizes in both the fixed- and random-effects models, and all effects were significant $(P<0.0001)$ except for TGF- $\beta$. However, other factors showed significant negative effect sizes in fixed- and random-effects models $(P<0.05)$. According to Kim et al. (2013), the administration of Aucklandia lappa in a murine IBD model was effective in improving the symptoms of IBD by decreasing IFN- $\gamma$, tumor necrosis factor $\alpha$ (TNF- $\alpha)$, and IL-6, and increasing TGF- $\beta$ and IL-10. Similarly, Jeon et al. (2016) found a significant decrease of TNF- $\alpha$, IL-1 $\beta$, IL- 6 , and IFN- $\gamma$ after administration of Zostera marina extract in a murine IBD model and the decreased colon length induced by administration of DSS was recovered.

These results showed that probiotic supplementation was effective in improving the symptoms of IBD, including contraction of colon length, increase in spleen weight, and scores related to inflammation. Colon length was significantly increased $(P<0.0001)$, and spleen weight, histological score, and inflammatory score were significantly decreased (i.e., improved; $P<$ 0.0001). Usually, destruction of the gut structure by widespread permeation of inflammatory cells, edema of the large intestine, and ulcers is found in people with IBD, leading to contraction of colon length (Wu et al., 2011). Thus, reduction in colon length can be a marker for the diagnosis of IBD (Yoda et al., 2014). The spleen is the largest organ in the lymphatic system, and it plays a major role in antibody formation, so it tends to enlarge as a result of infection (King and Shumacker, 1952).

Cytokines are secreted by activated lymphocytes and macrophages, and regulate the function of cells associated with the cell-mediated immune response. They also play an important role in the inflammatory response (Zhang and An, 2007). Recently, cytokines have been recognized as key players in the pathophysiology of IBD (Kim et al., 2003). One of the proinflammatory cytokines is TNF- $\alpha$, which plays an important role in immune response expression and regulation. An increase in TNF- $\alpha$ has been observed in the mucosa of people with IBD (Dionne et al., 1997). Interferon- $\gamma$ is a protein with antiviral activity, and 3 IFN types, $\alpha$, $\beta$, and $\gamma$, activate immunocytes. Among these, IFN- $\gamma$ is secreted by $\mathrm{T}$ cells and natural killer cells and acts as a macrophage-activating factor (Tau and Rothman, 1999). The cytokine IL-1 $\beta$ is an intermediator of inflammatory response, and inflammation-inducing factor in acute or chronic IBD (Tau and Rothman, 1999). Cytokine IL-6 is generated in activated T cells and is known to be induced in the stage at which $\mathrm{B}$ cells differentiate into antibody-producing cells (Barnes

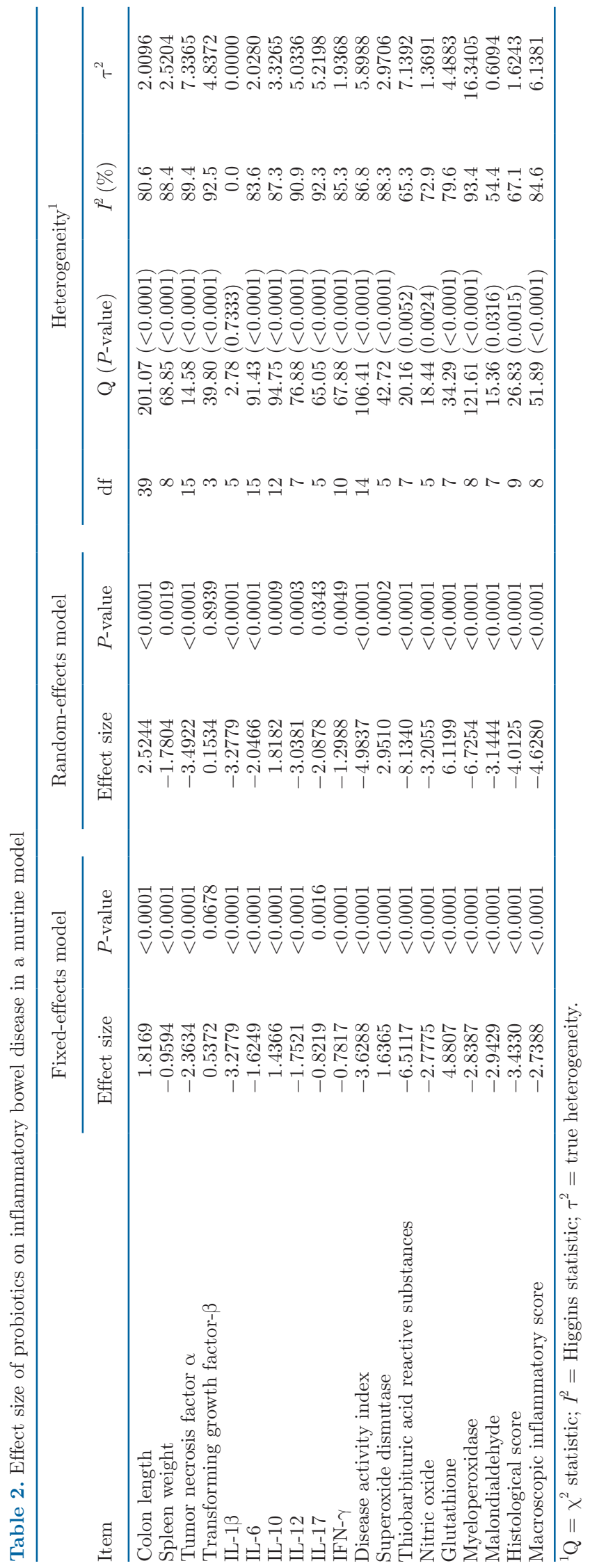


and Karin, 1997). Finally, IL-10 is known as a cytokine inhibitor; it regulates inflammatory responses by inhibiting the secretion of IFN- $\gamma$ and IL-2. Levels of IL-10 are decreased in people with IBD, and clinical manifestations and endoscopic improvements have been observed with IL-10 supplementation in people with IBD (Tau and Rothman, 1999; Fedorak et al., 2000; Schreiber et al., 2000).

As the secretion of IL-10 and TGF- $\beta$ increases, the symptoms of IBD decrease. In contrast, the secretion of IFN- $\gamma$, TNF- $\alpha$, IL-17, and IL-6 induces symptoms of IBD (Jeon et al., 2016). According to the results of the current meta-analysis, IL-10 and TGF- $\beta$ showed a positive effect size, and IFN- $\gamma$, TNF- $\alpha$, IL-17, and IL-6 showed negative effect sizes, with significant differences $(P<0.0001)$. However, the effect size of TGF- $\beta$ was not significant $(P>0.05)$. These results suggest that the proinflammatory cytokines may be inhibited by probiotic supplementation. As well, these results were consistent with the findings of Lee et al. (2008), who reported that probiotic supplementation could improve IBD by suppressing the biosynthesis of proinflammatory cytokines.

Pawar et al. (2011) and Nieto et al. (2000) showed that reactive oxygen species (ROS) also mediate inflammation along with proinflammatory cytokines, and ROS can contribute to the inflammatory chain reaction regulating the immune system that is associated with IBD. Injury mediated by oxidants plays a leading part in the pathophysiology of IBD (Byrne and Viney, 2006; Neuman, 2007; Oz and Ebersole, 2008). Reduced glutathione and antioxidant activity leads to disease progression. Moreover, ROS mediators enhance the production of proinflammatory biomolecules such as IL-1 $\beta$, IL-6, and TNF- $\alpha$. These inflammatory markers are increased in people with IBD and in IBD animal models (Zhong et al., 2006). An increase in proinflammatory biomolecules correlates with the downregulation of antioxidant activity; thus, activating ROS results in intestinal inflammation. An increase in antioxidants attenuates the level of TNF- $\alpha$ and reduces inflammation in IBD (Oz et al., 2005, 2007). Consequently, oxidative and nitrosative stresses are strongly associated with IBD progression and healing of gut injury (Koppikar et al., 2014).

Nitric oxide is vigorously reactive, and its molecules are always present in the biological system (Petersson et al., 2007). It is related to inflammation and other pathological states. In addition, malondialdehyde, a volatile compound involved in lipid peroxidation, is assayed for thiobarbituric acid using the thiobarbituric acid reactive substances (TBARS) test (Koppikar et al., 2014). In the present study, TBARS, nitric oxide, and malondialdehyde showed negative effect sizes $(P<$ 0.0001 ), indicating that supplementation with probiotics effectively protected the gut mucosa from oxidative stress. Furthermore, antioxidants such as superoxide dismutase and reduced glutathione were significantly increased after probiotic supplementation $(P<0.0001)$. This may be due to antioxidants derived from yogurt fermented with probiotics. Kudoh et al. (2001) isolated a DPPH (2,2-diphenyl-1-picrylhydrazyl) radical-scavenging peptide derived from $\kappa$-casein in yogurt fermented with Lactobacillus bulgaricus. Sah et al. (2014) observed antioxidant activity in yogurt fermented with various strains of probiotics.

In the present study, we calculated Q statistics and $I^{2}$ values to evaluate the heterogeneity of the effect sizes. High Q statistics and significantly low $P$-values denote statistically high heterogeneity among studies. Moreover, when the $\mathrm{Q}$ statistic is greater than the degrees of freedom, the likelihood of study heterogeneity is statistically significant, but it depends on the number of studies (Fleiss, 1986). In the current study, the highest Q statistics were detected for colon length, which was significant $(P<0.0001)$ and greater than the degrees of freedom. To resolve the disadvantage of the $\mathrm{Q}$ statistics, we used $I^{2}$ values to analyze heterogeneity (Higgins et al., 2003). For most factors, $I^{2}$ values were above $70 \%$ in the included studies, indicating that most factors had significant levels of heterogeneity. In particular, the $I^{2}$ and $\tau^{2}$ values for myeloperoxidase were the highest, at $93.4 \%$ and 16.3405 , respectively, and those for IL-1 $\beta$ were the lowest, at $0 \%$ and 0 , respectively.

\section{Moderator Analysis}

The results of the analysis revealed significant heterogeneity among the analyzed studies, so we performed an additional moderator analysis. We conducted meta-ANOVA on factors with sufficient sample sizes, including colon length, TNF- $\alpha$, IL-6, IL-10, IFN- $\gamma$, and disease activity index. As shown in Table 3, supplementation with Lactobacillus paracasei showed the greatest effect size in terms of colon length. After unification of the variance between subgroups $\left(\tau^{2}\right)$, we tested subgroup differences. The $\mathrm{Q}$ statistic between groups $\left(\mathbf{Q}_{\mathbf{b}}\right)$ was $37.66(\mathrm{df}=12 ; P=0.0002)$, and the effect size between groups was assumed to be significantly different. We then used meta-regression to analyze the effect size between probiotics groups (Table 4) and found that the effects of $L$. paracasei $(P<0.0001)$, L. plantarum $(P=0.0046)$, and Lactobacillus rhamnosus $(P=0.009)$ were significant. Among them, L. paracasei was the most effective probiotic in preventing the shrinkage of colon length caused by IBD. For TNF- $\alpha$, a mixture of 


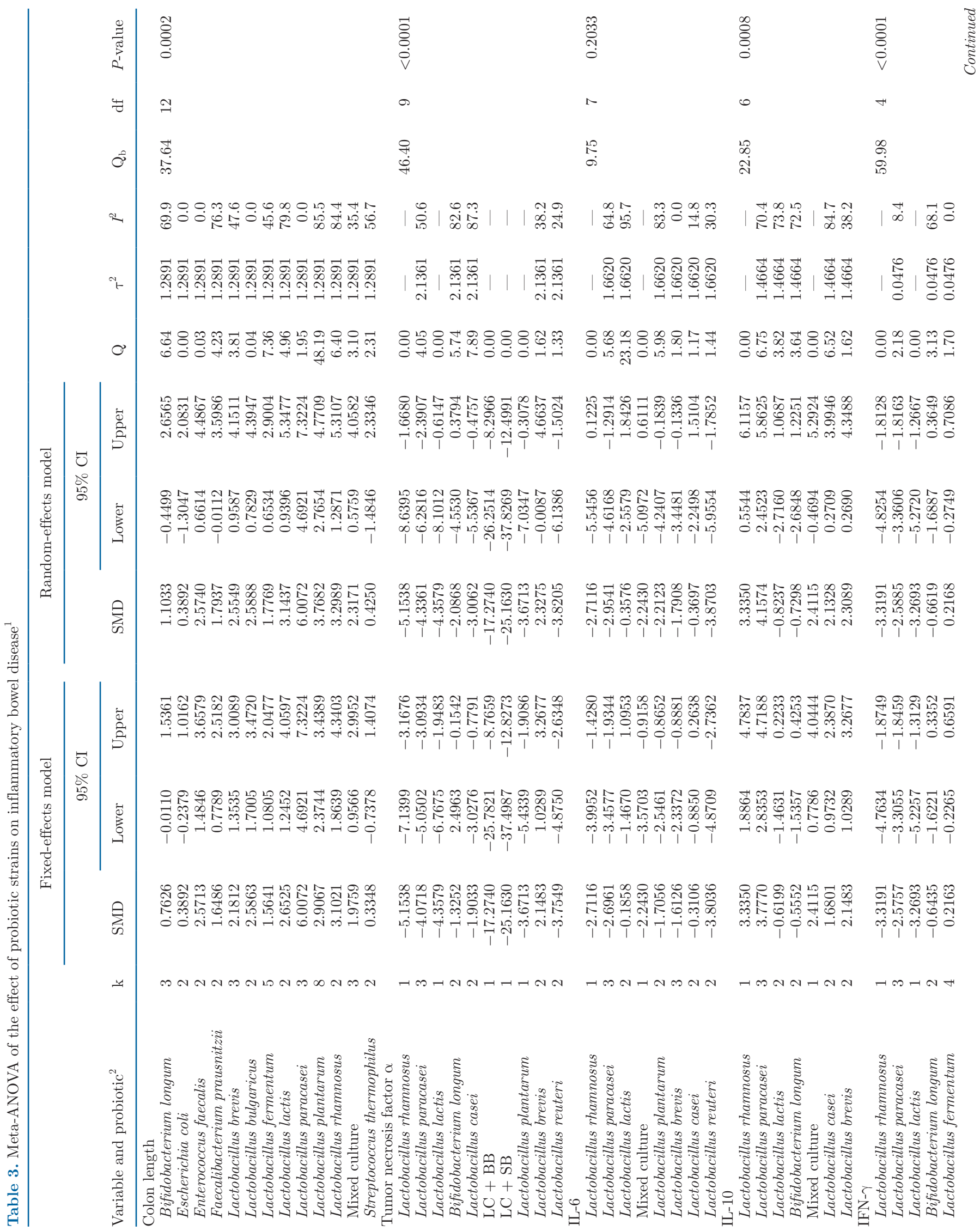




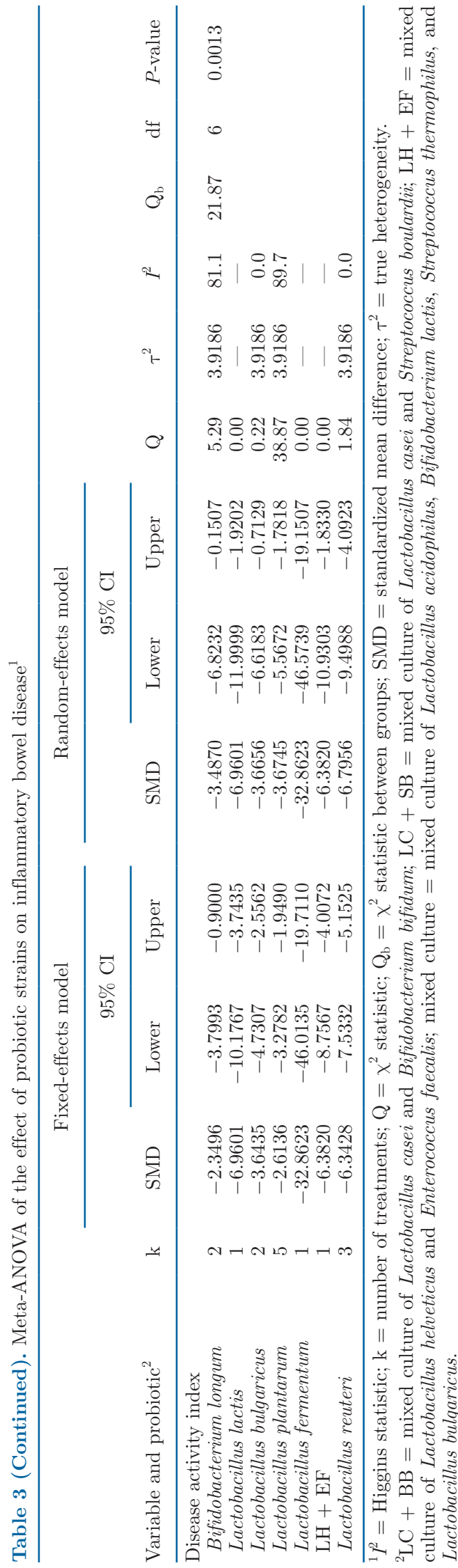

L. bulgaricus and $S$. boulardii showed the greatest effect size, and after the unification of $\tau^{2}, \mathrm{Q}_{\mathrm{b}}$ was 46.40 . In meta-regression tests, the mixture of $L$. bulgaricus and $S$. boulardii and a mixture of $L$. casei and Bifidobacterium bifidum showed significant differences $(P=0.0005$ and 0.0014, respectively). For IFN- $\gamma, L$. paracasei and $L$. rhamnosus showed the highest effect size, and the $\mathrm{Q}_{\mathrm{b}}$ was $53.61(\mathrm{df}=4 ; P<0.0001)$, indicating that the effect size between the groups had a significant difference. Meta-regression testing also indicated significant differences $(P=0.0033$ and 0.0043 , respectively). Also according to the meta-regression tests, the $R^{2}$ values were 70.88 and 97.54 , respectively, suggesting that the regression models had high explanatory power.

Traditionally, sulfasalazine, 5-aminosalisylic acid, corticosteroids, and anti-TNF drugs have been used to treat IBD (Choi et al., 2017). These treatments improve IBD symptoms resulting from the reduction of prostaglandin; the attenuation of T-lymphocytes; the synthesis of IL-1, IL-2, IL-8, and NF-kB; and the inhibition of protein secretion related to inflammation, such as collagenase, elastase, and plasminogen activators (Shanahan et al., 1990; Cominelli et al., 1992; Bantel et al., 2000; Choi and Choi, 2005). However, these treatments have been associated with side effects such as headache, nausea, fever, interstitial nephritis, anemia, and reversible male sterility (Levi et al., 1979; Kornbluth and Sachar, 2010).

The administration of probiotics is related to the expression of anti-inflammatory cytokines, which induce TGF- $\beta$ expression and attenuate the symptoms of IBD (Torii et al., 2007). Treatment of IBD with probiotics has been reported to demonstrate positive effects. Schultz et al. (2002) reported that onset of IBD could be prevented and established colitis reduced in IL10-deficient mice by treatment with L. plantarum $299 \mathrm{v}$. Mao et al. (1996) reported that the administration of L. plantarum $299 \mathrm{v}$ could delay the onset and reduce the severity of colitis. Lactobacillus reuteri (R2LC) abated colitis in mice with IL-10 deficiency (Madsen et al., 1999). Gupta et al. (2000) showed that the administration of L. rhamnosus GG to people with IBD for $6 \mathrm{mo}$ led to a decrease in clinical disease activity. Kruis et al. (1997) reported that the probiotics-treated group in their study showed a similar relapse rate to the mesalazine group. Guslandi et al. (2000) found that combined treatment with $S$. boulardii and 5-aminosalisylic acid reduced the relapse rate from 38 to $6 \%$ after 6 mo of treatment. Malchow (1997) reported that the relapse rate was reduced by combination treatment with prednisolone and probiotics. The administration of probiotics could be effective in improving the symptoms of IBD and could be a promising alternative for IBD treatment. 


\section{Publication Bias}

We examined publication bias with respect to the factors we investigated, including colon length, TNF- $\alpha$, IL-6, IL-10, IFN- $\gamma$, and disease activity index, using funnel plots (Figure 1) and Egger's linear regression test (Table 5). As shown in Figure 1, we found publication bias for all factors. Although we found some asymmetry in the funnel plot for IL-10 (Figure 1F), we did not detect significance in the Egger's linear regression test. However, we found significant differences in the other groups $(P<0.05)$, indicating that the

Table 4. Meta-regression analysis of the effect of probiotic strains on inflammatory bowel disease ${ }^{1}$

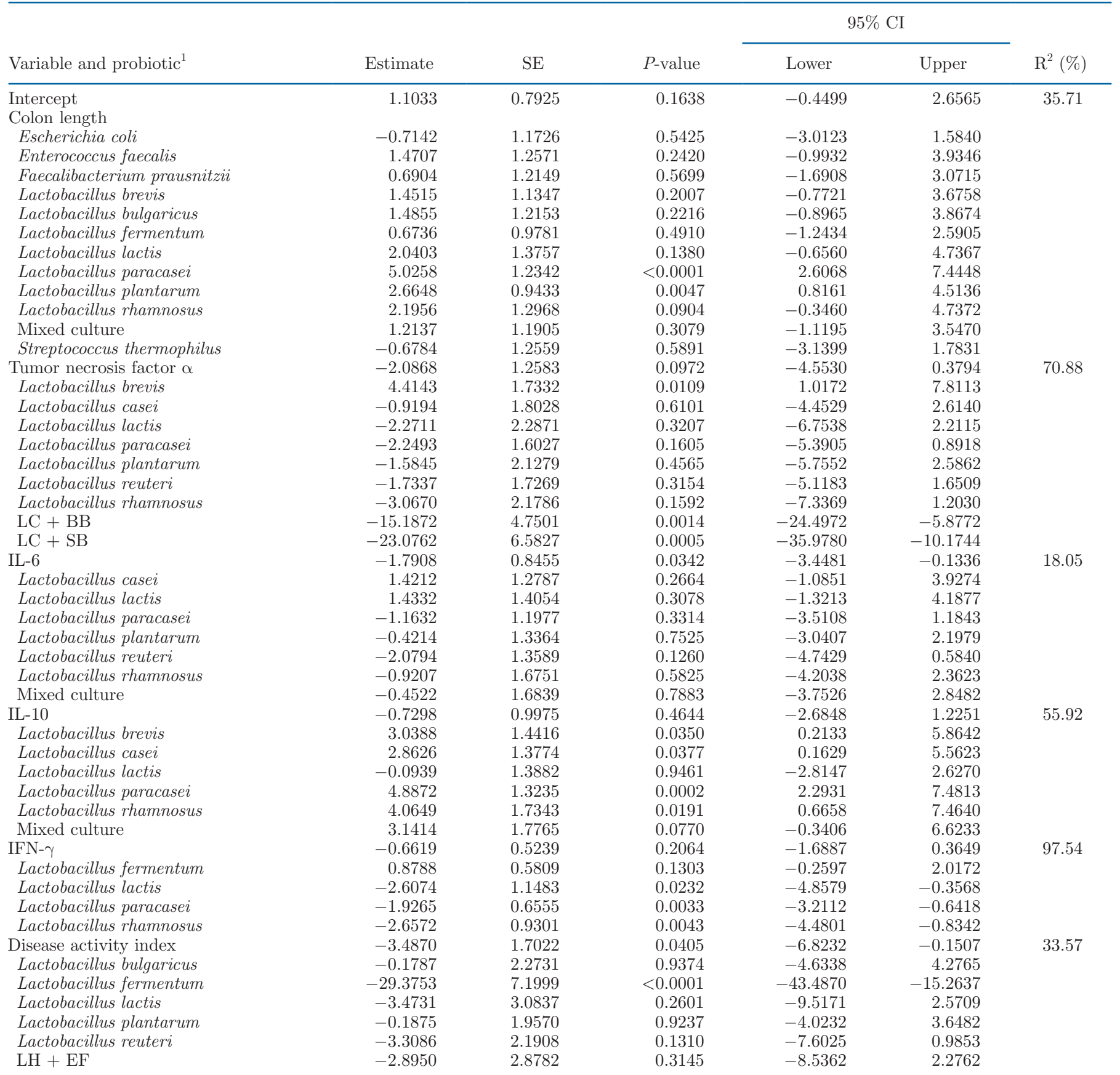

${ }^{1} \mathrm{LC}+\mathrm{BB}=$ mixed culture of Lactobacillus casei and Bifidobacterium bifidum; $\mathrm{LC}+\mathrm{SB}=$ mixed culture of Lactobacillus casei and Streptococcus boulardii , LH $+\mathrm{EF}=$ mixed culture of Lactobacillus helveticus and Enterococcus faecalis; mixed culture $=$ mixed culture of Lactobacillus acidophilus, Bifidobacterium lactis, Streptococcus thermophilus, and Lactobacillus bulgaricus. 
Table 5. Egger's linear regression test for publication bias

\begin{tabular}{|c|c|c|c|c|c|c|}
\hline Item & Bias & SE & Slope & T-value & df & $P$-value \\
\hline Tumor necrosis factor $\alpha$ & -4.757640 & 1.6531910 & 1.680228 & -2.8779 & 14 & 0.0122 \\
\hline IL-6 & -5.198753 & 1.8272670 & 1.485141 & -2.8451 & 14 & 0.1297 \\
\hline IFN- $\gamma$ & -8.328726 & 1.8856970 & 3.832194 & -4.4168 & 9 & 0.0017 \\
\hline Disease activity index & -5.528796 & 1.0101130 & 1.049389 & -5.4734 & 13 & $<0.0001$ \\
\hline
\end{tabular}

Table 6. Trimmed effect size of probiotics on inflammatory bowel disease in a murine model

\begin{tabular}{|c|c|c|c|c|c|c|c|c|}
\hline Item & df & \multicolumn{2}{|c|}{ Fixed-effects model } & \multicolumn{2}{|c|}{ Random-effects model } & \multicolumn{3}{|c|}{ Heterogeneity $^{1}$} \\
\hline Colon length & 53 & 1.3283 & $<0.0001$ & 1.4327 & $<0.0001$ & $387.83(<0.0001)$ & 86.3 & 3.6251 \\
\hline IL-6 & 20 & -1.1730 & $<0.0001$ & -1.2636 & 0.0018 & $150.11(<0.0001)$ & 86.8 & 2.8866 \\
\hline IL-10 & 14 & 1.1641 & $<0.0001$ & 1.2697 & 0.0248 & $126.64(<0.0001)$ & 89.0 & 4.1485 \\
\hline IFN- $\gamma$ & 13 & -0.3717 & 0.0211 & -0.5586 & 0.2514 & $112.92(<0.0001)$ & 88.5 & 2.8561 \\
\hline
\end{tabular}

${ }^{1} \mathrm{Q}=\chi^{2}$ statistic $I^{2}=$ Higgins statistic; $\tau^{2}=$ true heterogeneity.

(A)

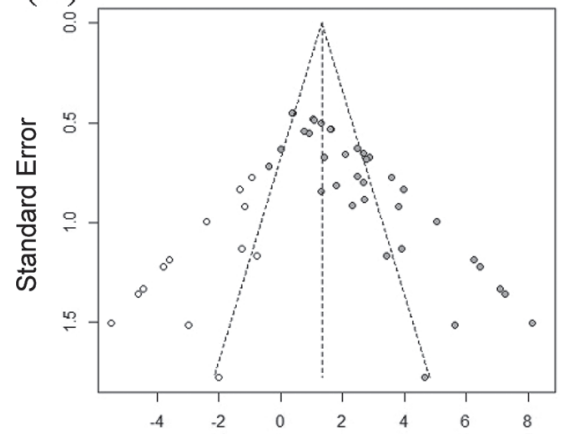

(D)

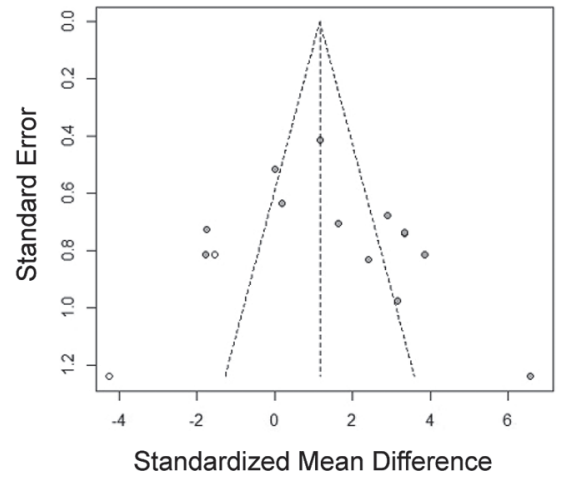

(B)

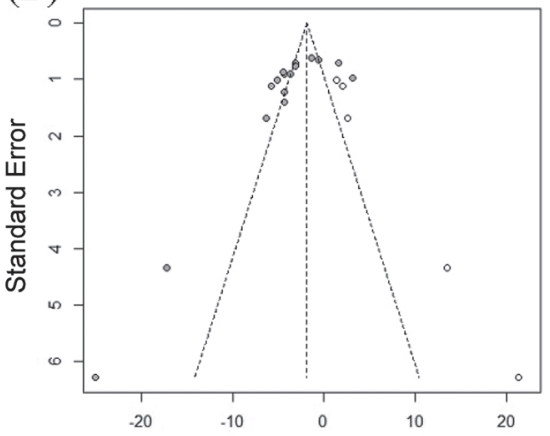

(E)

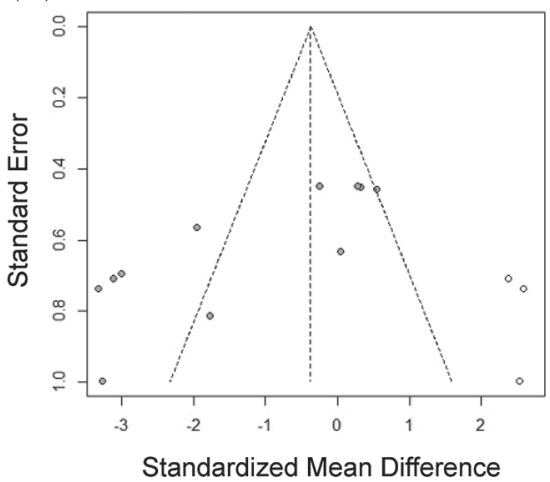

(C)

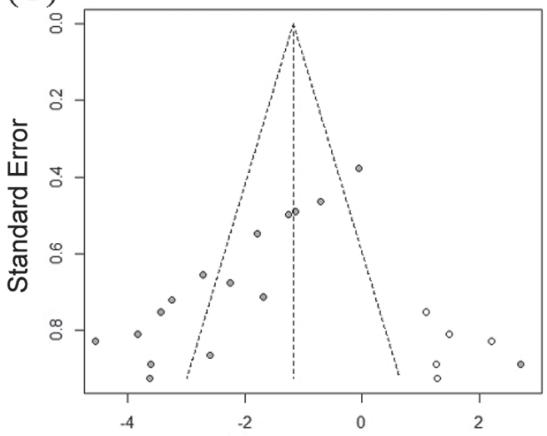

(F)

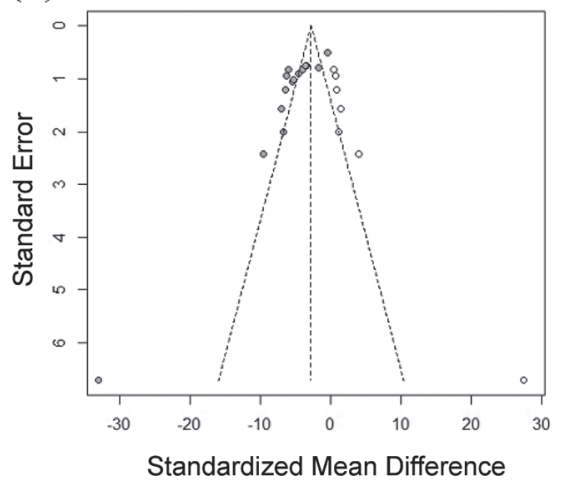

Figure 1. Funnel plots to evaluate publication bias: (A) colon length; (B) tumor necrosis factor $\alpha$; (C) IL-6; (D) IL-10; (E) IFN- $\gamma$; and (F) disease activity index. 
relationship between effect size and standard error is statistically significant, and it can statistically prove the asymmetry of the funnel plots (Egger et al., 1997). Thus, we used the trim-and-fill procedure to arrange asymmetry for all factors, and the resulting trimmed effect sizes are listed in Table 6. Most of the effects were significant $(P<0.05)$, except for IFN- $\gamma$. Colon length and IL-10 showed a positive effect size, and the other factors showed negative effect sizes.

\section{CONCLUSIONS}

This study showed the effect of probiotic supplementation on IBD, synthesizing the results by metaanalysis. We found that probiotics can help improve the symptoms of IBD. The present study had some limitations, one being the lack of meta-analysis results from animal experiments. However, this meta-analysis will be useful for future studies on probiotics for people with IBD.

\section{ACKNOWLEDGMENTS}

This study was supported by the Cooperation Research Program for Agriculture Science and Technology Development (PJ01197802), Rural Development Administration, Republic of Korea.

\section{REFERENCES}

Ahl, D., H. Liu, O. Schreiber, S. Roos, M. Phillipson, and L. Holm. 2016. Lactobacillus reuteri increases mucus thickness and ameliorates dextran sulphate sodium-induced colitis in mice. Acta Physiol. (Oxf.) 217:300-310. https://doi.org/10.1111/apha.12695.

Bantel, H., C. Berg, M. Vieth, M. Stolte, W. Kruis, and K. SchulzeOsthoff. 2000. Mesalazine inhibits activation of transcription factor NF-kappa B in inflamed mucosa of patients with ulcerative colitis. Am. J. Gastroenterol. 95:3452-3457.

Barnes, P. J., and M. Karin. 1997. Nuclear factor-KB - A pivotal transcription factor in chronic inflammatory disease. N. Engl. J. Med. 336:1066-1071. https://doi.org/10.1056/NEJM199704103361506.

Borenstein, M., L. V. Hedges, J. Higgins, and H. R. Rothstein. 2009. Introduction to Meta-Analysis. John Wiley \& Sons, West Sussex, UK.

Boumpas, D. T., G. P. Chrousos, and R. L. Wilder. 1993. Glucocorticoid therapy for immune-mediated diseases: Basic and clinical correlates. Ann. Intern. Med. 119:1198-1208. https://doi.org/10 .7326/0003-4819-119-12-199312150-00007.

Byrne, F. R., and J. L. Viney. 2006. Mouse models of inflammatory bowel disease. Curr. Opin. Drug Discov. Devel. 9:207-217.

Celiberto, L. S., R. Bedani, N. N. Dejani, A. Ivo de Medeiros, J. A. Sampaio Zuanon, L. C. Spolidorio, M. A. Tallarico Adorno, M. B. Amâncio Varesche, F. Carrilho Galvão, S. R. Valentini, G. Font de Valdez, E. A. Rossi, and D. C. U. Cavallini. 2017. Effect of a probiotic beverage consumption (Enterococcus faecium CRL 183 and Bifidobacterium longum ATCC 15707) in rats with chemically induced colitis. PLoS One 12:e0175935. https://doi.org/10.1371/ journal.pone.0175935.

Chauhan, R., A. Sudhakaran Vasanthakumari, H. Panwar, R. H. Mallapa, R. K. Duary, V. K. Batish, and S. Grover. 2014. Amelioration of colitis in mouse model by exploring antioxidative potentials of an indigenous probiotic strain of Lactobacillus fermentum
Lf1. BioMed Res. Int. 2014:1-12. https://doi.org/10.1155/2014/ 206732.

Chen, C. L., P. Y. Hsu, and T. M. Pan. 2019. Therapeutic effects of Lactobacillus paracasei ssp. paracasei NTU 101 powder on dextran sulfate sodium-induced colitis in mice. J. Food Drug Anal. 27:83-92.

Choi, C. H., W. Moon, Y. S. Kim, E. S. Kim, B. I. Lee, Y. Jung, Y S. Yoon, H. Lee, D. I. Park, and D. S. Han. 2017. Second Korean guideline for the management of ulcerative colitis. Korean J. Gastroenterol. 69:1-28. https://doi.org/10.4166/kjg.2017.69.1.1.

Choi, E. J., H. J. Lee, W. J. Kim, K. I. Han, M. Iwasa, K. Kobayashi, T. Debnath, Y. Tang, Y. S. Kwak, J. H. Yoon, and E. K. Kim. 2019. Enterococcus faecalis EF-2001 protects DNBS-induced inflammatory bowel disease in mice model. PLoS One 14:e0210854. https://doi.org/10.1371/journal.pone.0210854.

Choi, H., and K. Y. Choi. 2005. Diagnosis and treatment of ulcerative colitis. J. Korean Med. Assoc. 48:154-166. https://doi.org/ 10.5124/jkma.2005.48.2.154

Chung, Y. W., J. H. Choi, T. Y. Oh, C. S. Eun, and D. S. Han. 2008 Lactobacillus casei prevents the development of dextran sulphate sodium-induced colitis in Toll-like receptor 4 mutant mice. Clin. Exp. Immunol. 151:182-189. https://doi.org/10.1111/j.1365-2249 $2007.03549 . \mathrm{x}$

Cominelli, F., R. D. Zipser, and C. A. Dinarello. 1992. Sulfasalazine inhibits cytokine production in human mononuclear cells: A novel anti-inflammatory mechanism. Gastroenterology 96:A96.

Deek, J. J., J. P. T. Higgins, and D. G. Altman. 2011. Analysing data and undertaking meta-analyses. Pages 243-293 in Cochrane Handbook for Systematic Reviews of Interventions. J. P. T. Higgins and S. Green, ed. John Wiley \& Sons, West Sussex, UK

Dionne, S., J. Hiscott, I. D'Agata, A. Duhaime, and E. G. Seidman. 1997. Quantitative PCR analysis of TNF-alpha and IL-1 beta mRNA levels in pediatric IBD mucosal biopsies. Dig. Dis. Sci. 42:1557-1566. https://doi.org/10.1023/A:1018895500721.

Egger, M., G. D. Smith, M. Schneider, and C. Minder. 1997. Bias in meta-analysis detected by a simple, graphical test. BMJ 315:629634. https://doi.org/10.1136/bmj.315.7109.629.

Fedorak, R. N., A. Gangl, C. O. Elson, P. Rutgeerts, S. Schreiber, G. Wild, S. B. Hanauer, A. Kilian, M. Cohard, A. LeBeaut, and B. Feagan. 2000. Recombinant human interleukin 10 in the treatment of patients with mild to moderately active Crohn's disease. Gastroenterology 119:1473-1482. https://doi.org/10.1053/gast.2000 .20229

Feng, X., J. Zhang, Y. Qian, R. Yi, P. Sun, J. Mu, X. Zhao, and J. L. Song. 2018. Preventative effects of Lactobacillus plantarum YS-3 on oxazolone-induced BALB/c colitis in mice. Appl. Biol. Chem. 61:355-363. https://doi.org/10.1007/s13765-018-0359-3.

Fiocchi, C. 1998. Inflammatory bowel disease: Etiology and pathogenesis. Gastroenterology. 115:182-205. https://doi.org/10.1016/ S0016-5085(98)70381-6.

Fleiss, J. L. 1986. Analysis of data from multiclinic trials. Control. Clin. Trials 7:267-275. https://doi.org/10.1016/0197-2456(86)90034-6.

Frank, D. N., A. L. St. Amand, R. A. Feldman, E. C. Boedeker, N. Harpaz, and N. R. Pace. 2007. Molecular-phylogenetic characterization of microbial community imbalances in human inflammatory bowel diseases. Proc. Natl. Acad. Sci. USA 104:13780-13785. https://doi.org/10.1073/pnas.0706625104.

Franke, A., T. Balschun, T. H. Karlsen, J. Sventoraityte, S. Nikolaus, G. Mayr, F. S. Domingues, M. Albrecht, M. Nothnagel, D. Ellinghaus, C. Sina, C. M. Onnie, R. K. Weersma, P. C. F. Stokkers, C. Wijmenga, M. Gazouli, D. Strachan, W. L. McArdle, S. Vermeire, P. Rutgeerts, P. Rosenstiel, M. Krawczak, M. H. Vatn, IBSEN study group, C. G. Mathew, and S. Schreiber. 2008. Sequence variants in IL10, ARPC2 and multiple other loci contribute to ulcerative colitis susceptibility. Nat. Genet. 40:1319-1323. https://doi .org/10.1038/ng.221.

Fuller, R. 1989. Probiotics in man and animals. J. Appl. Bacteriol 66:365-378. https://doi.org/10.1111/j.1365-2672.1989.tb05105.x.

Ghasemi-Niri, S. F., A. H. Abdolghaffari, S. Fallah-Benakohal, M. Hosseinpour-Feizi, P. Mahdaviani, H. Jamalifar, M. Baeeri, G. Dehghan, and M. Abdollahi. 2011. On the benefit of whey-cul- 
tured Lactobacillus casei in murine colitis. J. Physiol. Pharmacol. 62:341-346.

Ghasemi-Niri, S. F., S. Solki, T. Diari, S. Mozaffari, M. Baeeri, M. A. Rezvanfar, A. Mohammadirad, H. Jamalifar, and M. Abdollahi. 2012. Better efficacy of Lactobacillus casei in combination with Bifidobacterium bifidum or Saccharomyces boulardii in recovery of inflammatory markers of colitis in rat. Asian J. Anim. Vet. Adv. https://doi.org/10.3923/ajava.2012.7:1148-1156.

Gholami, M., S. F. Ghasemi-Niri, F. Maqbool, M. Baeeri, Z. Memariani, I. Pousti, and M. Abdollahi. 2016. Experimental and pathological study of Pistacia atlantica, butyrate, Lactobacillus casei and their combination on rat ulcerative colitis model. Pathol. Res. Pract. 212:500-508. https://doi.org/10.1016/j.prp.2016.02.024.

Guarner, F., and G. J. Schaafsma. 1998. Probiotics. Int. J. Food Microbiol. 39:237-238. https://doi.org/10.1016/S0168-1605(97)00136 -0 .

Guinane, C. M., and P. D. Cotter. 2013. Role of the gut microbiota in health and chronic gastrointestinal disease: Understanding a hidden metabolic organ. Therap. Adv. Gastroenterol. 6:295-308. https://doi.org/10.1177/1756283X13482996.

Gupta, P., H. Andrew, B. S. Kirschner, and S. Guandalini. 2000. Is Lactobacillus GG helpful in children with Crohn's disease? Results of a preliminary open-label study. J. Pediatr. Gastroenterol. Nutr. 31:453-457. https://doi.org/10.1097/00005176-200010000-00024.

Guslandi, M., G. Mezzi, M. Sorghi, and P. A. Testoni. 2000. Saccharomyces boulardii in maintenance treatment of Crohn's disease. Dig. Dis. Sci. 45:1462-1464. https://doi.org/10.1023/A:1005588911207.

Hemarajata, P., and J. Versalovic. 2013. Effects of probiotics on gut microbiota: Mechanisms of intestinal immunomodulation and neuromodulation. Therap. Adv. Gastroenterol. 6:39-51. https://doi .org/10.1177/1756283X12459294.

Hendrickson, B. A., R. Gokhale, and J. H. Cho. 2002. Clinical aspects and pathophysiology of inflammatory bowel disease. Clin. Microbiol. Rev. 15:79-94. https://doi.org/10.1128/CMR.15.1.79-94.2002.

Higgins, J. P. T., S. G. Thompson, J. J. Deeks, and D. G. Altman. 2003. Measuring inconsistency in meta-analyses. BMJ 327:557560. https://doi.org/10.1136/bmj.327.7414.557.

Hill, C., F. Guarner, G. Reid, G. R. Gibson, D. J. Merenstein, B. Pot, L. Morelli, R. B. Canani, H. J. Flint, S. Salminen, P. C. Calder, and M. E. Sanders. 2014. The international scientific association for probiotics and prebiotics consensus statement on the scope and appropriate use of the term probiotic. Nat. Rev. Gastroenterol. Hepatol. 11:506-514. https://doi.org/10.1038/nrgastro.2014.66.

Hong, Y. S., Y. T. Ahn, J. C. Park, J. H. Lee, H. Lee, C. S. Huh, D. H. Kim, D. H. Ryu, and G. S. Hwang. 2010. ${ }^{1}$ H NMR-based metabonomic assessment of probiotic effects in a colitis mouse model. Arch. Pharm. Res. 33:1091-1101. https://doi.org/10.1007/s12272 -010-0716-1.

Jang, S. E., S. R. Hyam, M. J. Han, S. Y. Kim, B. G. Lee, and D. H. Kim. 2013. Lactobacillus brevis G-101 ameliorates colitis in mice by inhibiting NF- $\kappa B$, MAPK and AKT pathways and by polarizing M1 macrophages to M2-like macrophages. J. Appl. Microbiol. 115:888-896. https://doi.org/10.1111/jam.12273.

Jeon, W. H., S. J. Ko, B. Ryu, and J. W. Park. 2016. Therapeutic and prophylactic effects of Zostera marina on dextran sulfate sodium-induced colitis. J. Korean Med. 37:13-26. https://doi.org/ $10.13048 / \mathrm{jkm} .16031$

Kim, E. R., and D. K. Chang. 2014. Colorectal cancer in inflammatory bowel disease: The risk, pathogenesis, prevention and diagnosis. World J. Gastroenterol. 20:9872-9881. https://doi.org/10.3748/ wjg.v20.i29.9872.

Kim, S. Y., J. W. Park, and B. H. Ryu. 2013. Effects of Aucklandia lappa on dextran sulfate sodium-induced murine colitis. Korean J. Intern. Med. 34:134-146.

Kim, T. H., B. G. Kim, H. D. Sin, J. W. Kim, C. G. Kim, J. S. Kim, H. C. Jeong, and I. S. Song. 2003. Alimentary tract: Tumor necrosis factor- $\alpha$ and interleukin-10 Gen polymorphisms in Korean patients with inflammatory bowel disease. Korean J. Gastroenterol. 42:377-386.

King, H., and H. B. Shumacker Jr.. 1952. Splenic studies: I. Susceptibility to infection after splenectomy performed in infancy. Ann.
Surg. 136:239-242. https://doi.org/10.1097/00000658-195208000 -00006 .

Kokesová, A., L. Frolová, M. Kverka, D. Sokol, P. Rossmann, J. Bartová, and H. Tlaskalová-Hogenová. 2006. Oral administration of probiotic bacteria (E. coli Nissle, E. coli O83, Lactobacillus casei) influences the severity of dextran sodium sulfate-induced colitis in BALB/c Mice. Folia Microbiol. (Praha) 51:478-484. https://doi .org $/ 10.1007 / \mathrm{BF} 02931595$.

Koppikar, S. J., S. D. Jagtap, P. P. Devarshi, N. M. Jangle, V. B. Awad, A. A. Wele, and A. M. Harsulkar. 2014. Triphala, an Ayurvedic formulation improves the antioxidant status on TNBS induced IBD in rats. Eur. J. Integr. Med. 6:646-656. https://doi .org/10.1016/j.eujim.2014.08.005.

Kornbluth, A., and D. B. Sachar. 2010. Ulcerative colitis practice guidelines in adults: American College of Gastroenterology, Practice Parameters Committee. Am. J. Gastroenterol. 105:501-523. https://doi.org/10.1038/ajg.2009.727.

Krawisz, J. E., P. Sharon, and W. F. Stenson. 1984. Quantitative assay for acute intestinal inflammation based on myeloperoxidase activity. Gastroenterology 87:1344-1350. https://doi.org/10.1016/0016 $-5085(84) 90202-6$.

Kruis, W., E. Schutz, P. Fric, B. Fixa, G. Judmaier, and M. Stolte. 1997. Double-blind comparison of an oral Escherichia coli preparation and mesalazine in maintaining remission of ulcerative colitis. Aliment. Pharmacol. Ther. 11:853-858. https://doi.org/10.1046/j .1365-2036.1997.00225.x.

Kudoh, Y., S. Matsuda, K. Igoshi, and T. Oki. 2001. Antioxidative peptide from milk fermented with Lactobacillus delbrueckii ssp. bulgaricus IFO13953. Nippon Shokuhin Kagaku Kogaku Kaishi 48:44-50. https://doi.org/10.3136/nskkk.48.44.

Kühbacher, T., S. J. Ott, U. Helwig, T. Mimura, F. Rizzello, B. Kleessen, P. Gionchetti, M. Blaut, M. Campieri, U. R. Fölsch, M. A. Kamm, and S. Schreiber. 2006. Bacterial and fungal microbiota in relation to probiotic therapy (VSL\#3) in pouchitis. Gut 55:833841. https://doi.org/10.1136/gut.2005.078303.

Lee, H. S., S. Y. Han, E. A. Bae, C. S. Huh, Y. T. Ahn, J. H. Lee, and D. H. Kim. 2008. Lactic acid bacteria inhibit proinflammatory cytokine expression and bacterial glycosaminoglycan degradation activity in dextran sulfate sodium-induced colitic mice. Int. Immunopharmacol. 8:574-580. https://doi.org/10.1016/j.intimp.2008.01 .009 .

Levi, A. J., A. M. Fisher, L. Hughes, and W. F. Hendry. 1979. Male infertility due to sulphasalazine. Lancet 314:276-278. https://doi .org/10.1016/S0140-6736(79)90292-7.

Li, G., X. Long, Y. Pan, X. Meng, and X. Zhao. 2018. Colitis reducing effects of Lactobacillus plantarum YS-4 in dextran sulfate sodium-induced C57BL/6J mice. Biomed. Res. (Aligarh) 29:768-774. https://doi.org/10.4066/biomedicalresearch.29-17-3436.

Liberati, A., D. G. Altman, J. Tetzlaff, C. Mulrow, P. C. Gøtzsche, J. P. Ioannidis, M. Clarke, P. J. Devereaux, J. Kleijnen, and D. Moher. 2009. The PRISMA statement for reporting systematic reviews and meta-analyses of studies that evaluate health care interventions: Explanation and elaboration. PLoS Med. 6:e1000100. https://doi.org/10.1371/journal.pmed.1000100.

Liu, Y. W., Y. W. Su, W. K. Ong, T. H. Cheng, and Y. C. Tsai. 2011. Oral administration of Lactobacillus plantarum K68 ameliorates DSS-induced ulcerative colitis in $\mathrm{BALB} / \mathrm{c}$ mice via the anti-inflammatory and immunomodulatory activities. Int. Immunopharmacol. 11:2159-2166. https://doi.org/10.1016/j.intimp .2011.09.013.

Luerce, T. D., A. C. Gomes-Santos, C. S. Rocha, T. G. Moreira, D. N. Cruz, L. Lemos, A. L. Sousa, V. B. Pereira, M. de Azevedo, K. Moraes, D. C. Cara, J. G. LeBlanc, V. Azevedo, A. M. C. Faria, and A. Miyoshi. 2014. Anti-inflammatory effects of Lactococcus lactis NCDO 2118 during the remission period of chemically induced colitis. Gut Pathog. 6:33-43. https://doi.org/10.1186/1757 $-4749-6-33$.

Madsen, K. L., J. S. Doyle, L. D. Jewell, M. M. Tavernini, and R. N. Fedorak. 1999. Lactobacillus species prevents colitis in interleukin-10 gene-deficient mice. Gastroenterology 116:1107-1114. https: //doi.org/10.1016/S0016-5085(99)70013-2. 
Malchow, H. A. 1997. Crohn's disease and Escherichia coli. A new approach in therapy to maintain remission of colonic Crohn's disease. J. Clin. Gastroenterol. 25:653-658. https://doi.org/10.1097/ 00004836-199712000-00021.

Mao, Y., S. Nobaek, B. Kasravi, D. Adawi, U. Stenram, G. Molin, and B. Jeppsson. 1996. The effects of Lactobacillus strains and oat fiber on methotrexate-induced enterocolitis in rats. Gastroenterology 111:334-344. https://doi.org/10.1053/gast.1996.v111.pm8690198.

Moeinian, M., S. F. Ghasemi-Niri, S. Mozaffari, A. H. Abdolghaffari, M. Baeeri, M. Navaea-Nigjeh, and M. Abdollahi. 2014. Beneficial effect of butyrate, Lactobacillus casei and L-carnitine combination in preference to each in experimental colitis. World J. Gastroenterol. 20:10876-10885. https://doi.org/10.3748/wjg.v20.i31.10876.

Moher, D., A. Liberati, J. Tetzlaff, and D. G. Altman.the PRISMA Group. 2009. Preferred reporting items for systematic reviews and metaanalyses: The PRISMA statement. PLoS Med. 6:e1000097. https://doi.org/10.1371/journal.pmed.1000097.

Misiewicz, J. J., J. E. Lennard-Jones, A. M. Connell, J. H. Baron, and F. Avery Jones. 1965. Controlled trial of sulfasalazine in maintenance therapy for ulcerative colitis. Lancet 285:185-188. https:// doi.org/10.1016/S0140-6736(65)90972-4.

Neuman, M. G. 2007. Immune dysfunction in inflammatory bowel disease. Transl. Res. 149:173-186. https://doi.org/10.1016/j.trsl.2006 .11 .009

Nieto, N., M. I. Torres, M. I. Fernández, M. D. Girón, A. Ríos, M. D. Suárez, and A. Gil. 2000. Experimental ulcerative colitis impairs antioxidant defense system in rat intestine. Dig. Dis. Sci. 45:18201827. https://doi.org/10.1023/A:1005565708038.

Nishitani, Y., T. Tanoue, K. Yamada, T. Ishida, M. Yoshida, T. Azuma, and M. Mizuno. 2009. Lactococcus lactis ssp. cremoris FC alleviates symptoms of colitis induced by dextran sulfate sodium in mice. Int. Immunopharmacol. 9:1444-1451. https://doi.org/10 .1016/j.intimp.2009.08.018.

Ogita, T., M. Nakashima, H. Morita, Y. Saito, T. Suzuki, and S. Tanabe. 2011. Streptococcus thermophilus ST28 ameliorates colitis in mice partially by suppression of inflammatory Th17 cells. J. Biomed. Biotechnol. 2011:1-9. https://doi.org/10.1155/2011/ 378417 .

Ott, S. J., T. Kühbacher, M. Musfeldt, P. Rosenstiel, S. Hellmig, A. Rehman, O. Drews, W. Weichert, K. N. Timmis, and S. Schreiber. 2008. Fungi and inflammatory bowel diseases: Alterations of composition and diversity. Scand. J. Gastroenterol. 43:831-841. https: //doi.org/10.1080/00365520801935434.

Oz, H. S., T. Chen, and H. Nagasawa. 2007. Comparative efficacies of two cysteine prodrugs and a glutathione delivery agent in a colitis model. Transl. Res. 150:122-129. https://doi.org/10.1016/ j.trsl.2006.12.010

Oz, H. S., T. S. Chen, C. J. McClain, and W. J. de Villiers. 2005. Antioxidants: A novel therapy in a murine model of colitis. J. Nutr. Biochem. 16:297-304. https://doi.org/10.1016/j.jnutbio.2004.09 .007 .

Oz, H. S., and J. L. Ebersole. 2008. Application of prodrugs to inflammatory diseases of the gut. Molecules 13:452-474. https://doi.org/ 10.3390 /molecules13020452.

Pawar, P., S. Gilda, S. Sharma, S. Jagtap, A. Paradkar, K. Mahadik, P. Ranjekar, and A. Harsulkar. 2011. Rectal gel application of Withania somnifera root extract expounds anti-inflammatory and mucorestorative activity in TNBS-induced inflammatory bowel disease. BMC Complement. Altern. Med. 11:34-42. https://doi .org/10.1186/1472-6882-11-34.

Petersson, J., O. Schreiber, A. Steege, A. Patzak, A. Hellsten, M. Phillipson, and L. Holm. 2007. eNOS involved in colitis-induced mucosal blood flow increase. Am. J. Physiol. Gastrointest. Liver Physiol. 293:G1281-G1287. https://doi.org/10.1152/ajpgi.00357 .2007.

Qian, Y., R. Yi, P. Sun, G. Li, and X. Ahao. 2017. Lactobacillus plantarum YS2 reduces oxazolone-induced colitis in $\mathrm{BALB} / \mathrm{c}$ mice. Biomed. Res. (Aligarh) 28:9242-9247.

Rembacken, B. J., A. M. Snelling, P. M. Hawkey, D. M. Chalmers, and A. T. R. Axon. 1999. Non-pathogenic Escherichia coli versus mesalizine for the treatment of ulcerative colitis: A ran- domised trial. Lancet 354:635-639. https://doi.org/10.1016/S0140 -6736(98)06343-0.

Sah, B. N. P., T. Vasiljevic, S. Mckechnie, and O. N. Donkor. 2014. Effect of probiotics on antioxidant and antimutagenic activities of crude peptide extract from yogurt. Food Chem. 156:264-270. https://doi.org/10.1016/j.foodchem.2014.01.105.

Salzman, N. H., and C. L. Bevins. 2008. Negative interactions with the microbiota: IBD. Adv. Exp. Med. Biol. 635:67-78. https://doi.org/ 10.1007/978-0-387-09550-9_6.

Santiago-López, L., A. Hernández-Mendoza, V. Mata-Haro, B. Vallejo-Córdoba, A. Wall-Medrano, H. Astiazarán-García, M. C. Estrada-Montoya, and A. F. González-Córdova. 2018. Effect of milk fermented with Lactobacillus fermentum on the inflammatory response in mice. Nutrients 10:1039. https://doi.org/10.3390/ nu10081039.

Santos Rocha, C., A. C. Gomes-Santos, T. Garcias-Moreira, M. de Azevedo, T. Diniz-Luerce, M. Mariadassou, A. P. Longaray Delamare, P. Langella, E. Maguin, V. Azevedo, A. M. Caetano de Faria, A. Miyoshi, and M. Van de Guchte. 2014. Local and systemic immune mechanisms underlying the anti-colitis effects of the dairy bacterium Lactobacillus delbrueckii. PLoS One 9:e85923. https:// doi.org/10.1371/journal.pone.0085923.

Sartor, R. B. 2008. Microbial influences in inflammatory bowel diseases. Gastroenterology 134:577-594. https://doi.org/10.1053/j .gastro.2007.11.059.

Scanlan, P. D., and J. R. Marchesi. 2008. Micro-eukaryotic diversity of the human distal gut microbiota: Qualitative assessment using culture-dependent and -independent analysis of faeces. ISME J. 2:1183-1193. https://doi.org/10.1038/ismej.2008.76.

Schreiber, O., J. Petersson, M. Phillipson, M. Perry, S. Roos, and L. Holm. 2009. Lactobacillus reuteri prevents colitis by reducing Pselectin-associated leukocyte- and platelet-endothelial cell interactions. Am. J. Physiol. Gastrointest. Liver Physiol. 296:G534-G542. https://doi.org/10.1152/ajpgi.90470.2008.

Schreiber, S., R. N. Fedorak, O. H. Nielsen, G. Wild, C. N. Williams, S. Nikolaus, M. Jacyna, B. A. Lashner, A. Gangl, P. Rutgeerts, K. Isaacs, S. J. H. Van Deventer, J. C. Koningsberger, M. Cohard, A. Le Beaut, and S. B. Hanauer. 2000. Safety and efficacy of recombinant human interleukin-10 in chronic active Crohn's disease. Gastroenterology 119:1461-1472. https://doi.org/10.1053/gast .2000 .20196

Schultz, M., C. Veltkamp, L. A. Dieleman, W. B. Grenther, P. B. Wyrick, S. L. Tonkonogy, and R. B. Sartor. 2002. Lactobacillus plantarum $299 \mathrm{v}$ in the treatment and prevention of spontaneous colitis in interleukin-10 deficient mice. Inflamm. Bowel Dis. 8:7180. https://doi.org/10.1097/00054725-200203000-00001.

Shanahan, F., A. Niederlehner, N. Carramanzana, and P. Anton. 1990 Sulfasalazine inhibits the binding of TNF alpha to its receptor. Immunopharmacology 20:217-224. https://doi.org/10.1016/0162 -3109(90)90037-F.

Sokol, H., B. Pigneur, L. Watterlot, O. Lakhdari, L. G. BermúdezHumarán, J. J. Gratadoux, S. Blugeon, C. Bridonneau, J. P. Furet, G. Corthier, C. Grangette, N. Vasquez, P. Pochart, G. Trugnan, G. Thomas, H. M. Blottière, J. Doré, P. Marteau, P. Seksik, and P. Langella. 2008. Faecalibacterium prausnitzii is an anti-inflammatory commensal bacterium identified by gut microbiota analysis of Crohn disease patients. Proc. Natl. Acad. Sci. USA 105:1673116736. https://doi.org/10.1073/pnas.0804812105.

Srutkova, D., M. Schwarzer, T. Hudcovic, Z. Zakostelska, V. Drab, A. Spanova, B. Rittich, H. Kozakova, and I. Schabussova. 2015. Bifidobacterium longum CCM 7952 promotes epithelial barrier function and prevents acute DSS-induced colitis in strictly strainspecific manner. PLoS One 10:e0134050. https://doi.org/10.1371/ journal.pone.0134050.

Tamboli, C. P., C. Neut, P. Desreumaux, and J. F. Colombel. 2004 Dysbiosis as a prerequisite for IBD. Gut 53:1057.

Tau, G., and P. Rothman. 1999. Biologic functions of the IFN- $\gamma$ receptors. Allergy 54:1233-1251. https://doi.org/10.1034/j.1398-9995 .1999.00099.x.

Torii, A., S. Torii, S. Fujiwara, H. Tanaka, N. Inagaki, and H. Nagai. 2007. Lactobacillus acidophilus strain L-92 regulates the production 
of Th1 cytokine as well as Th2 cytokines. Allergol. Int. 56:293-301. https://doi.org/10.2332/allergolint.O-06-459.

Toumi, R., K. Abdelouhab, H. Rafa, I. Soufli, D. Raissi-Kerboua, Z. Djeraba, and C. Touil-Boukoffa. 2013. Beneficial role of the probiotic mixture ultrabiotique on maintaining the integrity of intestinal mucosal barrier in DSS-induced experimental colitis. Immunopharmacol. Immunotoxicol. 35:403-409. https://doi.org/10.3109/ 08923973.2013 .790413$.

Weitzman, S. A., and L. I. Gordon. 1990. Inflammation and cancer: Role of phagocyte-generated oxidants in carcinogenesis. Blood 76:655-663. https://doi.org/10.1182/blood.V76.4.655.655.

Wu, L. H., Z. L. Xu, D. Dong, S. A. He, and H. Yu. 2011. Protective effect of anthocyanins extract from blueberry on TNBS-included IBD model of mice. Evid. Based Complement. Alternat. Med. 2011: 1-8. https://doi.org/10.1093/ecam/neq040.

Yoda, K., K. Miyazawa, M. Hosoda, M. Hiramatsu, F. Yan, and F. He. 2014. Lactobacillus GG-fermented milk prevents DSS-induced colitis and regulates intestinal epithelial homeostasis through activation of epidermal growth factor receptor. Eur. J. Nutr. 53:105-115. https://doi.org/10.1007/s00394-013-0506-X.

Yoon, J. W., S. I. Ahn, J. W. Jhoo, and G. Y. Kim. 2019. Antioxidant activity of yogurt fermented at low temperature and its anti-in- flammatory effect on DSS-induced colitis in mice. Food Sci. Anim. Resour. 39:162-176. https://doi.org/10.5851/kosfa.2019.e13.

Zhang, J. M., and J. An. 2007. Cytokines, inflammation and pain. Int. Anesthesiol. Clin. 45:27-37. https://doi.org/10.1097/AIA $.0 \mathrm{~b} 013 \mathrm{e} 318034194 \mathrm{e}$

Zhang, M., X. Qiu, H. Zhang, X. Yang, N. Hong, Y. Yang, H. Chen, and C. Yu. 2014. Faecalibacterium prausnitzii inhibits interleukin-17 to ameliorate colorectal colitis in rats. PLoS One 9:e109146. https://doi.org/10.1371/journal.pone.0109146.

Zhong, J., E. Eckhart, H. S. Oz, D. Bruemmer, and W. de Villiers. 2006. Osteopontin deficiency protects mice from dextran sodium sulfate-induced colitis. Inflamm. Bowel Dis. 12:790-796. https:// doi.org/10.1097/00054725-200608000-00015.

\section{ORCIDS}

Sung-Il Ahn 주 https://orcid.org/0000-0001-8229-6420

Sangbuem Cho 1 h https://orcid.org/0000-0002-5637-9692

Nag-Jin Choi @ https://orcid.org/0000-0003-0145-8905 